\title{
Antimicrobial susceptibility testing for Helicobacter pylori isolates from Brazilian children and adolescents: Comparing agar dilution, E-test, and disk diffusion
}

\author{
Silvio Kazuo Ogata ${ }^{1}$, Ana Cristina Gales ${ }^{2}$, Elisabete Kawakami ${ }^{1}$ \\ ${ }^{1}$ Disciplina de Gastroenterologia Pediátrica, Hepatologica e Nutrição, Escola Paulista de Medicina, \\ Universidade Federal de São Paulo, São Paulo, SP, Brazil. \\ ${ }^{2}$ Laboratório Especial de Microbiologia Clínica, Departamento de Doenças Infecciosas, Escola Paulista \\ de Medicina, Universidade Federal de São Paulo, São Paulo, SP, Brazil.
}

Submitted: October 22, 2013; Approved: April 17, 2014.

\begin{abstract}
Antimicrobial susceptibility testing for Helicobacter pylori is increasingly important due to resistance to the most used antimicrobials agents. Only agar dilution method is approved by CLSI, but it is difficult to perform routinely. We evaluated the reliability of E-test and disk diffusion comparing to agar dilution method on Helicobacter pylori antimicrobial susceptibility testing. Susceptibility testing was performed for amoxicillin, clarithromycin, furazolidone, metronidazole and tetracycline using E-test, disk-diffusion and agar dilution method in 77 consecutive Helicobacter pylori strains from dyspeptic children and adolescents. Resistance rates were: amoxicillin - 10.4\%, 9\% and 68.8\%; clarithromycin - $19.5 \%, 20.8 \%, 36.3 \%$; metronidazole - $40.2 \% 33.7 \%, 38.9 \%$, respectively by agar dilution, E-test and disk diffusion method. Furazolidone and tetracycline showed no resistance rates. Metronidazole presented strong correlation to E-test $(\mathrm{r}=0.7992, \mathrm{p}<0.0001)$ and disk diffusion method $(\mathrm{r}=-0.6962, \mathrm{p}<0.0001)$. Clarithromycin presented moderate correlation to E-test $(\mathrm{r}=0.6369$, $\mathrm{p}<0.0001)$ and disk diffusion method $(\mathrm{r}=-0.5656, \mathrm{p}<0.0001)$. Amoxicillin presented weak correlation to E-test $(\mathrm{r}=0.3565, \mathrm{p}=0.0015)$ and disk diffusion $(\mathrm{r}=-0.3565, \mathrm{p}=0.0015)$. Tetracycline presented weak correlation with E-test $(r=0.2346, p=0.04)$ and furazolidone to disk diffusion $(\mathrm{r}=-0.0288, \mathrm{p}=0.8038)$. E-test presented better agreement with gold standard. It is an easy and reliable method for Helicobacter pylori susceptibility testing. Disk diffusion method presented high disagreement and high rates of major errors.
\end{abstract}

Key words: Helicobacter pylori, E-test, disk diffusion, susceptibility test.

\section{Introduction}

Consensus recommends triple therapy to eradicate Helicobacter pylori in infected children (Chey \& Wong, 2007; Fock et al., 2009; Jones et al., 2005; Malfertheiner et al., 2012). However in developing countries increasingly antimicrobial resistance, mainly to metronidazole and clarithromycin, is observed (Alvarez et al., 2009; Mendonça et al., 2000; Ogata et al., 2013; Sherif et al., 2004; Wong et al., 2003) and empirical treatment presents the risk of eradication failure and/or development of secondary resistance (Kalach et al., 2002; Molina-Infante \& Gisbert, 2013; Nguyen et al., 2012; Wong et al., 2003). Thus, antimi- crobial susceptibility testing for Helicobacter pylori is growing in importance (Chey \& Wong, 2007; Graham \& Fischbach, 2010; Kalach et al., 2002; Malfertheiner et al., 2012; Mégraud, 2004; Sykora \& Rowland, 2011).

Therefore, it is necessary to validate a reproducible in vitro susceptibility test to support the choice of antimicrobials drugs to eradicate $H$. pylori. The Clinical and Laboratory Standards Institute (CLSI) (National Committee for Clinical Laboratory Standards, Approved standard M7-A5, Informational supplement M100-S10, 2000) has approved only agar dilution method, but it is time-consuming, labor-intensive, and useful to simultaneously test a large number of strains. It is not adaptable to small numbers of strains, 
becoming impractical to perform routinely (Mégraud \& Lehours, 2007). Two alternative methods have been reported, the Epsilometer test (E-test) and the disk diffusion method. The E-test is a plastic strip containing increasing gradients of antimicrobial concentration (AB Biodisk, Solna, Sweden), and the MIC is read directly from the intersection of the elliptical zone of growth inhibition. This is the current recommended phenotypic method, due to a stable pattern of antibiotic release and a tolerance to prolonged incubation, being an accurate method to test a fastidious organism like H. pylori. This is the main reason for why E-test, and not disk diffusion method, has been recommended for Helicobacter pylori susceptibilty testing. But it is more expensive (US\$ $2.60 \mathrm{vs.} \mathrm{US \$} \mathrm{0.026)} \mathrm{(Mishra} \mathrm{et} \mathrm{al.,} \mathrm{2006).}$

The disk diffusion uses a disk with a known concentration of antimicrobial, it is simple and easy to perform, economical, and adaptable to clinical practice. But its a qualitative method, results can be only susceptible or resistant. And it is not standardized.

The difficulty to recommend one of these tests are the discrepancies between the methods and a lack of standardization to laboratory tests (Alarcon et al., 1998; Best et al., 2003; Glupczynski et al., 2002; Grignon et al., 2002; Hachem et al., 1996; Lang \& Garcia, 2004; Midolo et al., 1997; Mishra et al., 2006). The purpose of this study was to assess the reliability of E-test and disk diffusion comparing to the agar dilution method to evaluate Helicobacter pylori antimicrobial susceptibility.

\section{Patients and Methods}

From February 2008 to August 2009, 77 consecutive Helicobacter pylori isolates were obtained from children and adolescents (range: $3-20$ years, mean age $=11.1 \pm 3.9 \mathrm{y}$, Median $=10.8$ years; M/F: 1:1.08) who underwent endoscopic examination to evaluate dyspeptic symptoms at Hospital São Paulo - Universidade Federal de São Paulo and Cândido Fontoura Children's Hospital, located respectively at the south and east side of São Paulo City, Brazil.

The study was approved by the Institutional Review Board of Universidade Federal de São Paulo and the legal responsible signed an informed consent form.

Biopsy sampling and bacterial strains: Two antral biopsy specimens were collected and transported in BrainHeart Infusion (BHI) broth + glycerol $(10 \%)$ at $4{ }^{\circ} \mathrm{C}$. Gastric biopsy specimens were homogenized and $5 \mu \mathrm{L}$ of the solution was inoculated into selective BHI agar base (DIFCO Lawrence, Kansas - USA) containing 7-10\% defibrinated sheep blood, vancomycin $(10 \mathrm{mg} / \mathrm{L})$, trimethoprim $(5 \mathrm{mg} / \mathrm{L})$, cefsulodin $(5 \mathrm{mg} / \mathrm{L})$ and amphotericin B $(5 \mathrm{mg} / \mathrm{L})$ (Helicobacter pylori selective Medium - Dent Supplement Oxoid - Basingstoke, Hampshire - UK). All plates were incubated for 10 days at $37{ }^{\circ} \mathrm{C}$ in a microaerobic atmosphere $\left(10 \% \mathrm{CO}_{2}, 85 \% \mathrm{~N}_{2}, 5 \% \mathrm{O}_{2}\right)$ at $95 \%$ humidity - Microaerobac - Probac do Brasil - São Paulo, Brazil). Helicobacter pylori
INCQS 00380 - ATCC 43504 strain was used as control. $H$. pylori isolates were confirmed based on colony morphology, positive urease, oxidase, and catalase reaction, and Gram staining. Isolates were stored at $-70^{\circ} \mathrm{C}$ in $\mathrm{BHI}$ broth containing glycerol $30 \%$ until performing susceptibility test.

Susceptibility tests were performed using five $\mathrm{mL}$ of frozen isolates that were subcultured on to BHI agar containing $10 \%$ defibrinated sheep blood and incubated for 3 days at $37^{\circ} \mathrm{C}$ under microaerophilic conditions. The colonies were suspended in BHI broth, adjusted to McFarland 4 turbidity standard (approximately $1 \times 10^{8} \mathrm{cfu} / \mathrm{mL}$ ), and then inoculated into Mueller-Hinton agar, according each method. The plates were incubated at $37^{\circ} \mathrm{C}$ under microaerophilic conditions $\left(5 \% \mathrm{O}_{2}, 10 \% \mathrm{CO}_{2}\right.$ and $85 \% \mathrm{~N}_{2}$ at $95 \%$ humidity) for $72 \mathrm{~h}$.

Agar dilution method was performed according to the Clinical Laboratory Standards Institute (CLSI) protocols (CLSI (2006) M7-A5). A multipoint replicating device was used to deliver $2 \mu \mathrm{L}$ of inoculums in each plate. Breakpoint to antimicrobials drugs recommendation was selected based on CLSI or literature citations. The final concentrations of clarithromycin (Abbott Laboratories - Chicago, Illinois USA), tetracycline, furazolidone and amoxicillin (Sigma Aldritch Chemie - Steinheim, Germany) ranged from 0.015 to $64 \mu \mathrm{g} / \mathrm{mL}$, while metronidazole (Sigma Aldritch Chemie Steinheim, Germany) concentration ranged from 0.015 to $256 \mu \mathrm{g} / \mathrm{mL}$. The MICs values were the lowest antibiotic concentration that completely inhibited visible growth of the bacteria.

E-test was performed to clarithromycin, tetracycline, metronidazole and amoxicillin. Antimicrobial concentration ranges from 0.016 to $256 \mu \mathrm{g} / \mathrm{mL}$. After inoculation the plates were dried at $37^{\circ} \mathrm{C}$, then plastic strips (E-test) containing increasing gradient of antimicrobial concentration (AB Biodisk, Solna, Sweden) were applied onto surface of agar plate. The MICs values were read as the interception of the elliptical zone of inhibition with the graded strip for the E test after $72 \mathrm{~h}$.

MIC interpretative criteria: There is no standardized MIC breakpoint for $H$. pylori, except to clarithromycin $(\mathrm{MIC} \geq 1 \mu \mathrm{g} / \mathrm{mL}$, and intermediary if $\mathrm{MIC}=0.5 \mu \mathrm{g} / \mathrm{mL})$. The MIC breakpoint for other antimicrobials was based on the literature (MIC $\geq 2 \mu \mathrm{g} / \mathrm{mL}$ to amoxicillin and furazolidone; $\geq 4 \mu \mathrm{g} / \mathrm{mL}$ to tetracycline, and, $\geq 8 \mu \mathrm{g} / \mathrm{mL}$ to metronidazole).

Disk diffusion uses disks containing $2 \mu \mathrm{g}$ of clarithromycin, furazolidone, metronidazole and amoxicillin that were placed on the dried and inoculated Mueller-Hinton agar plates, results were read based on the diameters of the zone growth inhibition. Metronidazole standard by CLSI to disk diffusion: susceptible $\geq 21 \mathrm{~mm}$, intermediary 16-21 mm, and resistant $<16 \mathrm{~mm}$ (Chaves et al., 1999). The breakpoint to other antimicrobials was based on previous studies with similar methodology: amoxicillin susceptible 
$\geq 25 \mathrm{~mm}$ and amoxicillin resistant $<25 \mathrm{~mm}$, clarithromycin susceptible $\geq 21 \mathrm{~mm}$ and clarithromycin resistant $<21 \mathrm{~mm}$, and furazolidone susceptible $\geq 13 \mathrm{~mm}$ and furazolidone resistant $<21 \mathrm{~mm}$.

\section{Statistical analysis}

The disagreement among the 3 tests was analysed by McNemars test. MIC values analysis between E-test and agar dilution, and MIC values analysis of agar dilution and the disk diffusion inhibition zone diameter was performed by Spearmans correlation test. Susceptibility tests were examined by error categorization.

\section{Results}

Figures 1-4 show the scattergrams comparing agar dilution and E-test MICs to metronidazole, amoxicillin, tetracycline and clarithromycin, scattergram comparing the diameter of inhibition zone of disk diffusion and agar dilution MIC to metronidazole, clarithromycin, amoxicillin and furazolidone is showed in figure 5-8. The overall rate of clarithromycin, furazolidone, metronidazole, tetracycline, and amoxicillin resistance is shown in Table 1. Metronidazol showed the highest resistance level: $40.2 \%, 33.7 \%$ and $39.9 \%$ by agar dilution method, E-test and disk diffusion, respectively. The $\mathrm{MIC}_{90}$ value for agar dilution and E-test was similar $\left(64 \mu \mathrm{g} / \mathrm{mL}, 3 \log _{2}\right.$ over recommended breakpoint). There was a strong correlation $(\mathrm{r}=0.7992, \mathrm{p}<0.0001)$ with agar dilution and E-test, 5 (6.5\%) isolates were discordant. When compared to disk diffusion, disagreement occurred in
$10 \%$. The intermediary susceptibility to metronidazole by disk difusion was observed in $27 / 77$ (35\%); these results were exluded because difficult in comparison to agar dilution method. Nevertheless, strong correlation $(\mathrm{r}=-0.6962$, $\mathrm{p}<0.0001$ ) was observed with disk diffusion and agar dilution (Table 2).

Clarithromycin presented resistance rate of $19.5 \%$ by agar dilution method and by E-test (20.8\%); $\mathrm{MIC}_{90}$ was observed near the breakpoint $(\leq 1 \mu \mathrm{g} / \mathrm{mL})$. Disk diffusion showed resistance in $38.9 \%$ (Table 1). Evaluating disagreement to E-test, clarithromycin presented one intermediary result by agar dilution that was resistant by E-test (1.3\%) but correlation was moderate $(\mathrm{r}=0.6369, \mathrm{p}<0.0001)$ and disagreement with disk diffusion occurred in $11.7 \%, 9$ strains were susceptible by agar dilution and resistant by disk diffusion, but correlation was moderate $(\mathrm{r}=-0.5656, \mathrm{p}<0.0001)$ (Table 2).

Amoxicillin showed $10.4 \%$ of resistance rate by agar dilution and $9 \%$ by E-test, but presented the highest resistance rate by disk diffusion $(68.8 \%$ ) (Table 1). Disagreement between E-test and agar dilution occurred in one strain, that was susceptible by agar dilution and resistant by E-test $(1.3 \%)$, but E-test showed a weak correlation $(\mathrm{r}=0.3565$, $\mathrm{p}=0.0015)$. Agar dilution presented the highest disagreement $(58.4 \%)$ and a weak correlation too $(\mathrm{r}=-0.3565$, $\mathrm{p}=0.0015)$ (Table 2).

Tetracycline presented no resistant strains $(0 \%)$ by agar dilution method and by E-test, but correlation was weak $(r=0.2346, p=0.04)$. Furazolidone showed no resistant strains $(0 \%)$ by agar dilution and by disk diffusion,

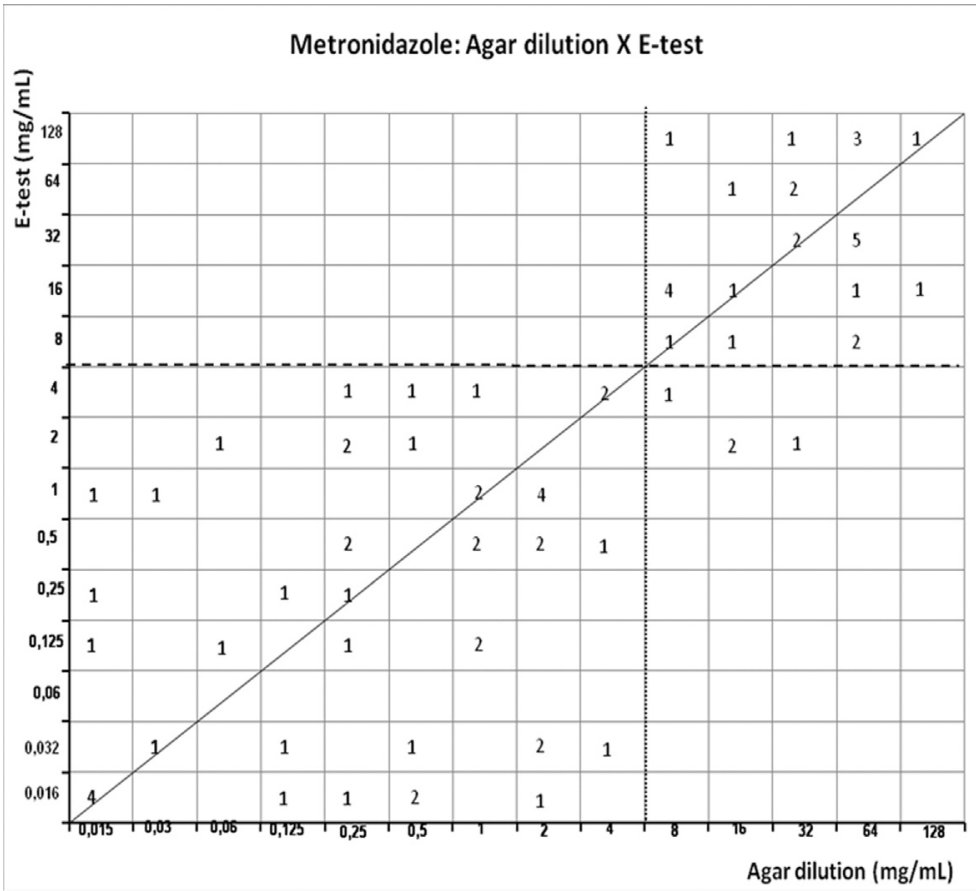

Figure 1 - Scattergram demostrating the correlation between agar dilution reference metronidazole MIC (resistant $\geq 8 \mu \mathrm{g} / \mathrm{mL}$ - dotted line) and E-test metronidazole MIC (resistant $\geq 8 \mu \mathrm{g} / \mathrm{mL}$ - dashed line) determined on Muller-Hinton agar. 


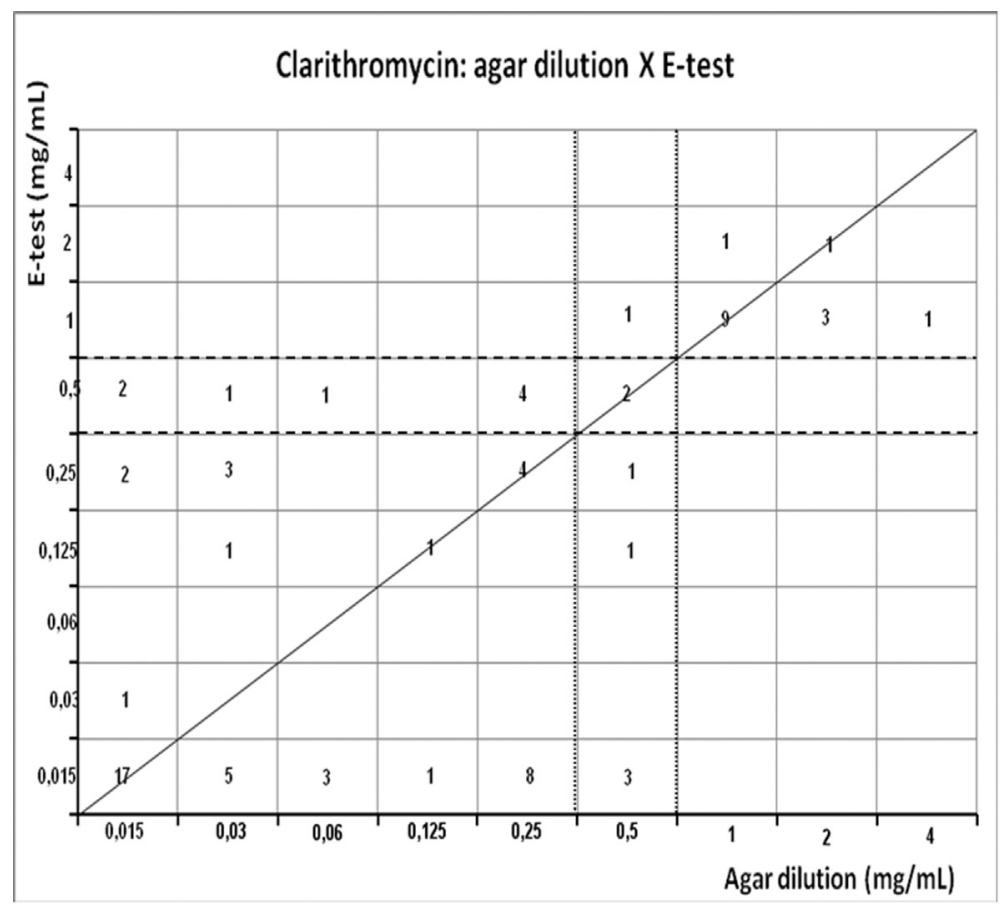

Figure 2 - Scattergram demostrating the correlation between agar dilution reference clarithromycin $\mathrm{MIC}$ (resistant $\geq 1 \mu \mathrm{g} / \mathrm{mL}$, and intermediary $=0.5$ $\mu \mathrm{g} / \mathrm{mL}$ - dotted line) and E-test clarithromycin MIC (resistant $\geq 1 \mu \mathrm{g} / \mathrm{mL}$, and intermediary $=0.5 \mu \mathrm{g} / \mathrm{mL}$ - dashed line) determined on Muller-Hinton agar.

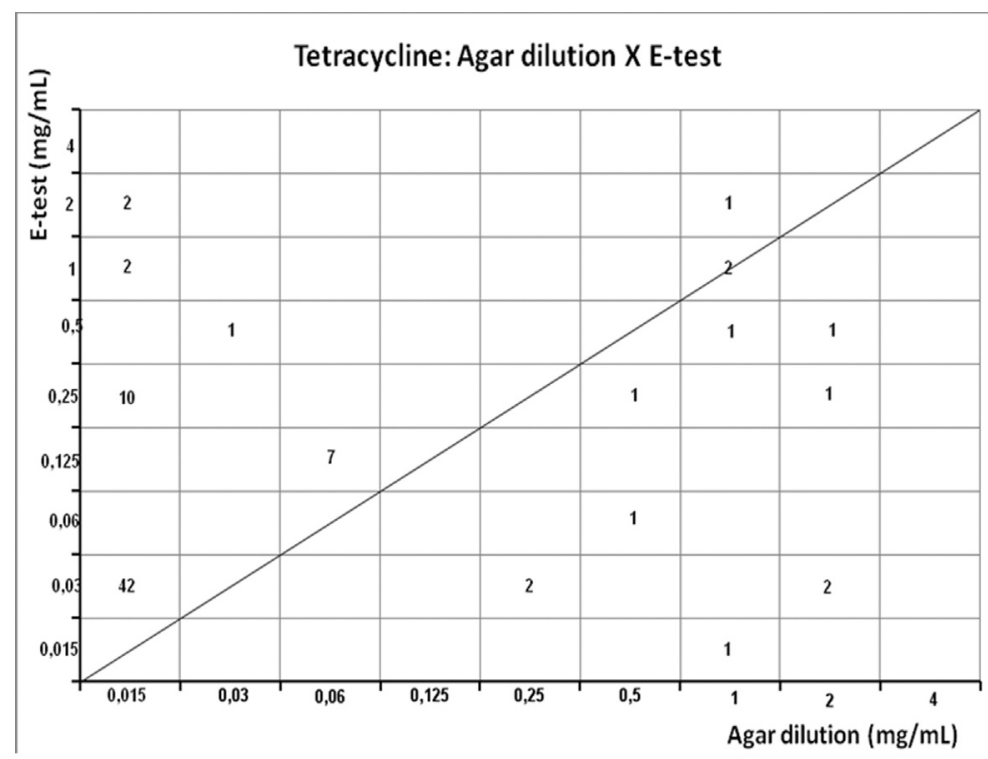

Figure 3 - Scattergram demostrating the correlation between agar dilution reference tetracycline MIC (resistant $\geq 4 \mu \mathrm{g} / \mathrm{mL}$ ) and E-test tetracycline MIC (resistant $\geq 4 \mu \mathrm{g} / \mathrm{mL}$ ) determined on Muller-Hinton agar.

and presented weak correlation too $(\mathrm{r}=-0.0288$, $\mathrm{p}=0.8038)$.

Interpretative error rate analysis (amoxicillin, clarithromycin and metronidazole)

\section{Very major error (VME)}

That occurred when the bacteria was resistant (agar dilution) and disk-diffusion method or E-test results were susceptible. In this situation the patients are treated with the antimicrobial, but eradication failure can occur;

\section{Major error (ME)}

When the bacteria was susceptible (agar dilution) and diffusion test disk or E-test showed resistance. In this situation the patient doesn't use the antimicrobial, but the treatment could work; 


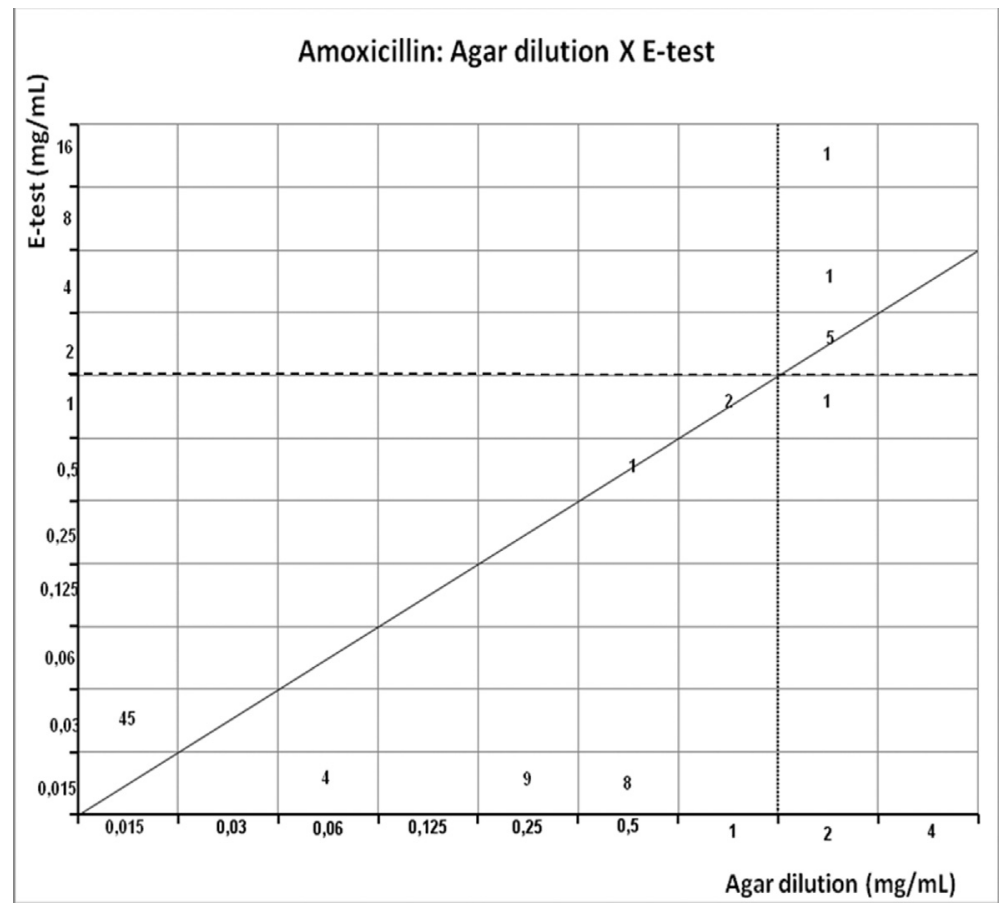

Figure 4 - Scattergram demostrating the correlation between agar dilution reference amoxicillin MIC (resistant $\geq 2 \mu \mathrm{g} / \mathrm{mL}$ - dotted line) and E-test amoxicillin MIC (resistant $\geq 2 \mu \mathrm{g} / \mathrm{mL}$ - dashed line) determined on Muller-Hinton agar.

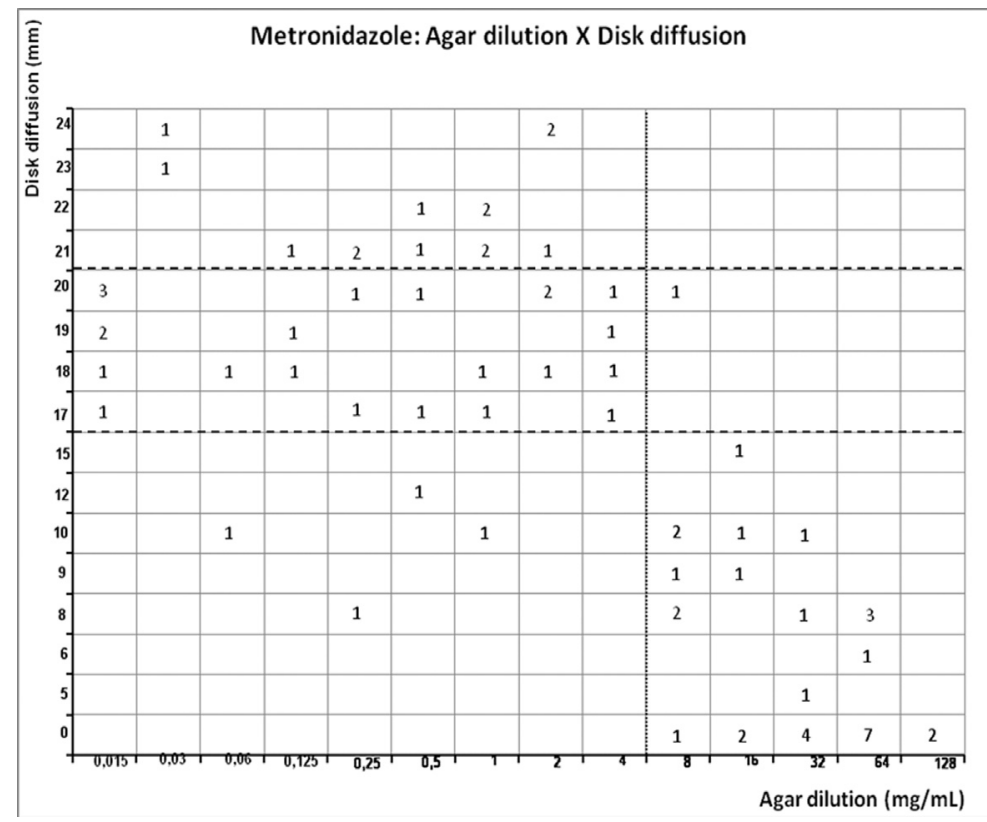

Figure 5 - Scattergram demostrating the correlation between agar dilution reference metronidazole MIC (resistant $\geq 8 \mu \mathrm{g} / \mathrm{mL}$ - dotted line) and disk diffusion metronidazole inhibition zone (susceptible $\geq 21 \mathrm{~mm}$, intermediary $16-21 \mathrm{~mm}$, and resistant $<16 \mathrm{~mm}$ - dashed line) determined on Muller-Hinton agar.

\section{Minor error (E)} tance.

The results where in the intermediary range of resis-

Disk diffusion method presented 94/231 (40.7\%) errors (59 ME and $35 \mathrm{E}$ ). E-test presented 13/107 (5.6\%) errors. Amoxicillin shows $1 \mathrm{VME}$ with E-test (1.3\%) and 45
ME by disk diffusion method (58.4\%). Clarithromycin showed $7(9.1 \%)$ errors by E-test, $1 \mathrm{ME}(1.3 \%)$ and 6 E (7.8\%), by disk diffusion 17 (22.1\%) errors occurred, $9 \mathrm{ME}(11.7 \%)$ and $8 \mathrm{E}(10.4 \%)$. Metronidazole presented the highest rate of VME by E-test - $5(6.5 \%)$, and by disk diffusion - $5 \mathrm{ME}(6.5 \%)$ and $27 \mathrm{E}(41.5 \%)$. 


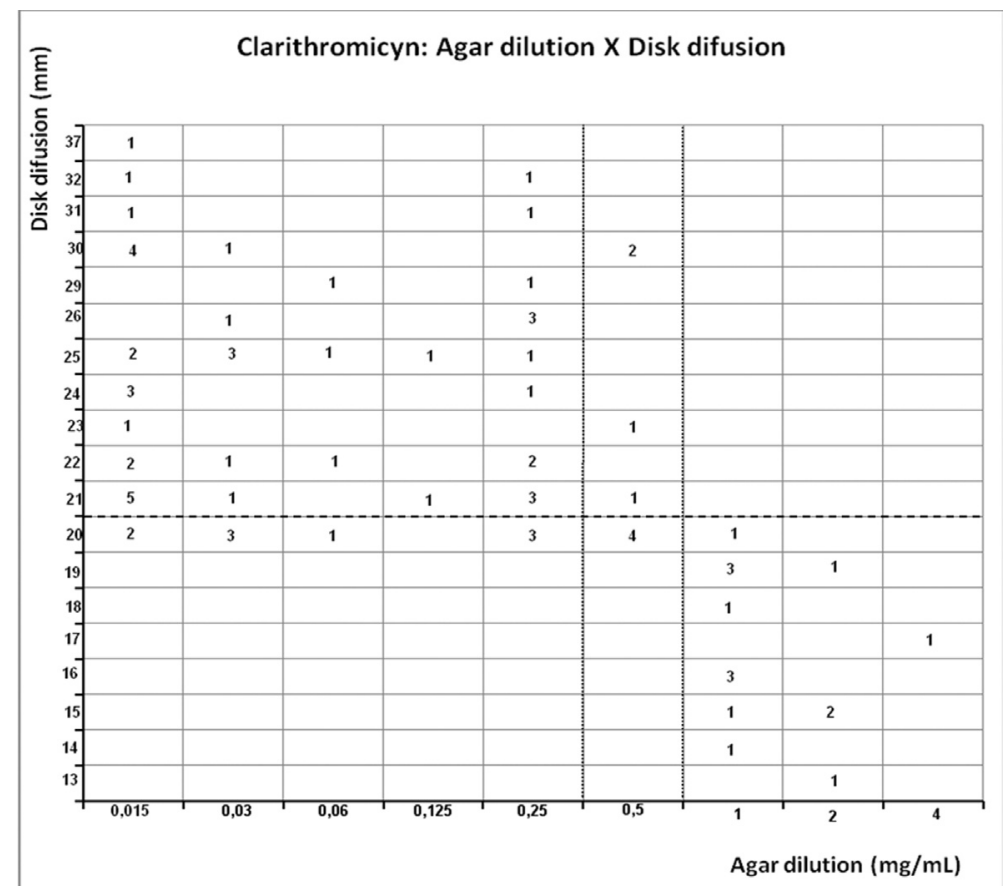

Figure 6 - Scattergram demostrating the correlation between agar dilution reference clarithromycin MIC (resistant $\geq 1 \mu \mathrm{g} / \mathrm{mL}$, and intermediary $=0.5$ $\mu \mathrm{g} / \mathrm{mL}$ - dotted line) and disk diffusion clarithromycin diameter of inhibition zone (resistant $<21 \mathrm{~mm}$ - dashed line) determined on Muller-Hinton agar.

\begin{tabular}{|c|c|c|c|c|c|c|c|c|c|}
\hline \multirow{4}{*}{ 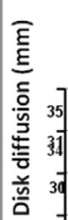 } & \multicolumn{9}{|c|}{ Furazolidone: Agar dilution X Disk diffusion } \\
\hline & 1 & 3 & & & 1 & & & & \\
\hline & 1 & & & & & 1 & & & \\
\hline & 5 & & & & & & & & \\
\hline 30 & 1 & 1 & & & 1 & & & & \\
\hline 28 & 1 & & 1 & & & & & & \\
\hline 26 & 9 & 1 & & & & & & & \\
\hline 25 & 6 & 1 & & & & 1 & & & \\
\hline 24 & 3 & 1 & 3 & & & 1 & & & \\
\hline 23 & 3 & 1 & & & 6 & & & & \\
\hline 22 & 7 & 3 & 1 & & & & & & \\
\hline 21 & 13 & 2 & & & & 6 & & & \\
\hline 20 & 17 & 2 & 1 & 25 & 1 & & & & \\
\hline 19 & 7 & 1 & 1 & & & & 2 & 3 & \\
\hline 18 & 1 & 1 & & & 9 & & & 5 & \\
\hline & 0,015 & 0,03 & 0,06 & 0,125 & 0,25 & 0,5 & 1 & 2 & 4 \\
\hline & & & & & & & & itic & $\mathrm{mL}$ ) \\
\hline
\end{tabular}

Figure 7 - Scattergram demostrating the correlation between agar dilution reference furazolidone MIC (resistant $\geq 4 \mathrm{mg} / \mathrm{mL}$ ) and disk diffusion furazolidone diameter of inhibition zone (susceptible $\geq 13 \mathrm{~mm}$ and resistant $<21 \mathrm{~mm}$ - dashed line) determined on Muller-Hinton agar.

\section{Technical and economical aspects}

The main differences were the price of each test (U\$ / sample) and the time consumed to prepare each one.

Agar dilution needs a sequencial dilution of antimicrobials and uses, in our study, 11 plates to be performed. It cost U\$ 37.26 and was the most laborious and timeconsuming test to prepare. However, we can evaluate 20 samples in each plate then the values can decrease to U\$ 1.86 / sample, but we need to collect all samples to perform the test.

E-test costs about U\$ 45.60, but was the easiest and simplest test to prepare. And each sample costs U\$23.49 to be evaluated by disk diffusion method. It is as simple to prepare as E-test. 


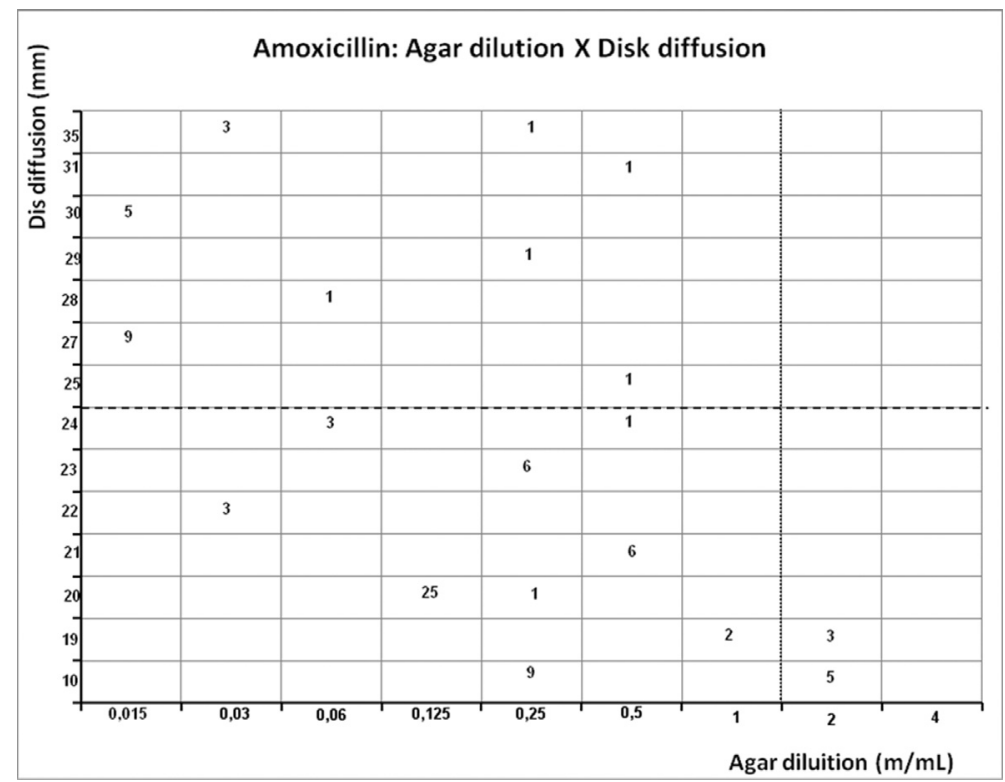

Figure 8 - Scattergram demostrating the correlation between agar dilution reference amoxicillin MIC (resistant $\geq 2 \mu \mathrm{g} / \mathrm{mL}$ - dotted line) and disk diffusion amoxicillin inhibition zone (resistant $<25 \mathrm{~mm}$ - dashed line) determined on Muller-Hinton agar.

Table 1 - Comparison of antimicrobials susceptibility test results by Agar dilution, E-test and Disk-diffusion method.

\begin{tabular}{|c|c|c|c|c|c|c|c|}
\hline \multirow[b]{2}{*}{ Method } & & & \multicolumn{5}{|c|}{ Antimicrobial Agent } \\
\hline & & & Amoxicillin & Clarithromycin & Furazolidone & Metronidazole & Tetracycline \\
\hline \multirow[t]{5}{*}{ Agar Dilution } & $\mathrm{MIC}(\mu \mathrm{g} / \mathrm{mL})$ & Range & $0.015-2$ & $0.015-4$ & $0.015-0.06$ & $0.015-256$ & $0.015-2$ \\
\hline & & $\mathrm{MIC}_{50}$ & 0.03 & 0.25 & 0.015 & 2.00 & 0.015 \\
\hline & & $\mathrm{MIC}_{90}$ & 1.00 & 1.00 & 0.03 & 64 & 1.00 \\
\hline & $\mathrm{N}(\%)$ of isolates & Sensitive & $69(89.6)$ & $62(80.5)$ & $77(100)$ & $46(59.8)$ & $77(100)$ \\
\hline & & Resistant & $8(10.4)$ & $15(19.5)$ & $0(0)$ & $31(40.2)$ & $0(0)$ \\
\hline \multirow[t]{5}{*}{ E-test } & $\operatorname{MIC}(\mu \mathrm{g} / \mathrm{mL})$ & Range & $0.016-16$ & $0.016-2$ & & $0.016-256$ & $0.016-2$ \\
\hline & & $\mathrm{MIC}_{50}$ & 0.032 & 0.125 & & 2 & 0.032 \\
\hline & & $\mathrm{MIC}_{90}$ & 1.00 & 1.00 & & 64 & 0.5 \\
\hline & $\mathrm{N}(\%)$ of isolates & Sensitive & $70(91)$ & $61(79.2)$ & & $51(66.2)$ & $77(100)$ \\
\hline & & Resistant & $7(9)$ & $16(20.8)$ & & $26(33.8)$ & $0(0)$ \\
\hline \multirow[t]{3}{*}{ Disk-Diffusion } & $\mathrm{mm}$ & Range & $10-35$ & $15-37$ & $18-35$ & 0 - 24 & \\
\hline & $\mathrm{N}(\%)$ of isolates & Sensitive & $24(31.2)$ & $45^{\mathrm{a}}(63.7)$ & $77(100)$ & $15^{\mathrm{b}}(18.2)$ & \\
\hline & & Resistant & $53(68.8)$ & $24^{\mathrm{a}}(36.3)$ & $0(0)$ & $35^{\mathrm{b}}(38.9)$ & \\
\hline
\end{tabular}

${ }^{a}$ Eight strains excluded because of intermediate results by agar dilution.

${ }^{\mathrm{b}}$ Twenty-seven strains excluded because of intermediate results by disk-difusion.

\section{Discussion}

Our results suggest that E-test is the best option to routinely performing susceptibility test for Helicobacter pylori. The results are similar to other studies that consider E-test a good method to clarithromycin and amoxicillin (Best et al., 2003; Glupczynski et al., 1991; Hachem et al., 1996), with good intra and interlaboratorial correlation (Glupczynski et al., 2002). Despite the price.

Agreement and disagreement analysis of E-test and agar dilution method showed the best agreement to tetracy- cline (100\%), followed by amoxicillin, clarithromycin and, metronidazole, all of them presented agreement rate over than $90 \%$. Evaluation of MIC values presented low correlation to amoxicillin, moderate to clarithromycin, and high to metronidazole. These results show that despite good agreement to discriminate susceptible and resistant isolates, MIC can present a large range between both methods. Even a variation of $2 \log _{2}$ in the MIC was not significant, not interfering in the interpretation of susceptible and resistant strains. 
Table 2 - Analysis of disagreement and correlation of agar diffusion methods (E-test and Disk-diffusion) compared to Agar dilution method.

\begin{tabular}{|c|c|c|c|c|}
\hline \multirow[t]{3}{*}{ Antimicrobial agent } & \multicolumn{4}{|c|}{ Method } \\
\hline & \multicolumn{2}{|c|}{ E-test } & \multicolumn{2}{|c|}{ Disk-diffusion } \\
\hline & Disagreement - \% (p) & Correlation $(\mathrm{p})$ & Disagreement - \% (p) & Correlation (p) \\
\hline Amoxicillin & $1.3(1)$ & $0.3565(0.0015)$ & $58.4(0.0001)$ & $-0.3565(0.0015)$ \\
\hline Clarithromycin & $1.3(1)$ & $0.6369(<0.0001)$ & $11.7(0.0077)$ & $-0.5656(<0.0001)$ \\
\hline Furazolidone & & & & $-0.0288(0.8038)$ \\
\hline Metronidazole & $6.5(0.07)$ & $0.7992(<0.0001)$ & $10(0.07)$ & $-0.6962(<0.0001)$ \\
\hline Tetracycline & & $0.2346(0.04)$ & & \\
\hline
\end{tabular}

Disagreement analysis - McNemar's test

Correlation analysis - Spearmans correlation test

Table 3 - Interpretative error rate analysis to E-test and disk-diffusion.

\begin{tabular}{|c|c|c|c|c|}
\hline Antimicrobial (N) & Error & E-test N (\%) & Disk-Diffusion N (\%) & Total N (\%) \\
\hline \multirow[t]{4}{*}{ Amoxicillin (77) } & Very major & $1(1.3)$ & 0 & $1(2.2)$ \\
\hline & Major & 0 & $45(58.4)$ & $45(97.8)$ \\
\hline & Minor & 0 & 0 & $46(100)$ \\
\hline & & $1(1.3)$ & $45(58.4)$ & \\
\hline \multirow[t]{4}{*}{ Clarithromycin (77) } & Very major & 0 & 0 & 0 \\
\hline & Major & $1(1.3)$ & $9(11.7)$ & $10(41.7)$ \\
\hline & Minor & $6(7.8)$ & $8(10.4)$ & $14(58.3)$ \\
\hline & & $7(9.1)$ & $17(22.1)$ & $24(100)$ \\
\hline \multirow[t]{4}{*}{ Metronidazole (77) } & Very major & $5(5.6)$ & 0 & $5(13.5)$ \\
\hline & Major & 0 & $5(5.6)$ & $5(13.5)$ \\
\hline & Minor & 0 & $27(35.9)$ & $27(73)$ \\
\hline & & $5(6.5)$ & $32(41.5)$ & $37(100)$ \\
\hline \multirow[t]{3}{*}{ Total } & Very major & $6(2.6)$ & 0 & $6(5.6)$ \\
\hline & Major & $1(0.4)$ & $59(25.5)$ & $60(56)$ \\
\hline & Minor & $6(2.6)$ & $35(15.2)$ & $41(38.3)$ \\
\hline 231 & & $13(5.6)$ & $94(40.7)$ & $107(100)$ \\
\hline
\end{tabular}

Metronidazole presented good correlation between agar dilution and E-test method. However, literature shows conflicting results. As our study, some authors observed high correlation with the agar dilution method (Best et al., 2003; Chaves et al., 1999; Osato, 2000; Tankovic et al., 2001). Chaves et al. (Chaves et al., 1999) did not observed significant differences between MIC of metronidazole by agar dilution and E-test. But there was discrepancy in other studies (Alarcon et al., 1998; Mégraud \& Lehours, 2007). The results of one study (Glupczynski et al., 2002) showed a good correlation to the antimicrobials, except to metronidazole that presented large range of inter and intralaboratorial values of MIC. This difference was large $\left(>2 \log _{2}\right)$ and authors recommend to test the isolates in parallel to improve the accuracy of E-test. The results need to be in acceptable level of MIC.

In opposition, disk diffusion method showed conflicting and inconsistent results to amoxicillin (break- point $=25 \mathrm{~mm}-41.6 \%$ ). The lack of standardization of the breakpoint is a difficulty, in addition to variations in the antimicrobial concentration in each disk. This study used disks containing $2 \mu \mathrm{g}$ and breakpoint based on previous studies with similar methodology. However, agreement with gold-standard was lower than other studies (Lang \& Garcia, 2004; Midolo et al., 1997; Sung et al., 2009).

Clarithromycin (breakpoint $=21 \mathrm{~mm}-83.1 \%$ ), is the unique antimicrobial standardized to disk diffusion (Grignon et al., 2002; Hachem et al., 1996; Midolo et al., 1997; Warburton-Timms \& McNulty, 2001). Comparing MIC by agar dilution and E-test we observed mild correlation, results that were comparable to other studies. When disk diffusion method used disks with $2 \mu \mathrm{g}$ of clarithromycin concentration ( $\mathrm{MIC}>2 \mathrm{mg} / \mathrm{L}$ ), discrepancies rarely occurred. The breakpoint $=22 \mathrm{~mm}$ to clarithromycin has the same discriminatory power than the MIC $>0.5 \mu \mathrm{g} / \mathrm{L}$ (Mégraud \& Lehours , 2007). 
Metronidazole showed agreement in $90 \%$ and mild correlation. Disk diffusion method to metronidazole was evaluated by Chaves et al. (Chaves et al., 1999), significant difference to MIC by agar dilution or disk diffusion was not observed using criteria of susceptible, intermediate and resistant. E-test and disk diffusion presented good correlation $(r=0.94)$. Interpretative error rate analysis shows major rate of errors using disk diffusion method. There is not a good agreement with agar dilution method. E-test, by the other hand, showed a good correlation and agreement.

\section{Conclusions}

E-test method presented better agreement with gold standard. It is an easy and reliable method to test Helicobacter pylori susceptibility. While, disk-diffusion method presented high disagreement with gold-standard and high rates of major errors. Probably a lack of breakpoint standardization, and different concentration of antimicrobial in diffusion disks are confouding factors. However, studies with a larger number of isolates are necessary to evaluate disk diffusion method that is simpler and cheaper.

\section{Financial Support Source}

Fundação de Amparo à Pesquisa do Estado de São Paulo - FAPESP

\section{Conflict of Interest}

No

\section{References}

Alarcon T, Domingo D, Lopez-Brea M (1998) Discrepancies between E-test and agar dilution methods for testing metronidazole susceptibility of Helicobacter pylori. J Clin Microbiol 36:1165-1166.

Alvarez A, Moncayo JI, Santacruz JJ, Santacoloma M, Corredor LF, Reinosa E (2009) Antimicrobial susceptibility and mutations involved in clarithromycin resistance in Helicobacter pylori isolates from patients in the western central region of Colombia. Antimicrob Agents Chemother 53:4022-4024.

Best LM, Haldane DJ, Keelan M, Taylor DE, Thomson AB, Loo V, Fallone CA, Lyn P, Smail FM, Hunt R, Gaudreau C, Kennedy J, Alfa M, Pelletier R, Veldhuyzen Van Zanten SJ (2003) Multilaboratory comparison of proficiencies in susceptibility testing of Helicobacter pylori and correlation between agar dilution and $\mathrm{E}$ test methods. Antimicrob Agents Chemother 47:3138-3144.

Chaves S, Gadanho M, Tenreiro R, Cabrita J (1999) Assessment of metronidazole susceptibility in Helicobacter pylori: Statistical validation and error rate analysis of breakpoints determined by the disk diffusion test. J Clin Microbial 37:1628-1631.

Chey WD \& Wong BC (2007) American College of Gastroenterology guideline on the management of Helicobacter pylori infection. Am J Gastroenterol 102:1808-1825.
Fock KM, Katelaris P, Sugano K, Ang TL, Hunt R, Talley NJ, Lam SK, Xiao SD, Tan HJ, Wu CY, Jung HC, Hoang BH, Kachintorn U, Goh KL, Chiba T, Rani AA (2009) Second Asia-Pacific Consensus Guidelines for Helicobacter pylori infection. J Gastroenterol Hepatol 24:1587-1600.

Glupczynski Y, Broutet N, Cantagrel A, Andersen LP, Alarcon T, Lopez-Brea M, Megraud F (2002) Comparison of the E test and agar dilution method for antimicrobial susceptibility testing of Helicobacter pylori. Eur J Clin Micrbiol Infect Dis 21:549-552.

Glupczynski Y, Labbe M, Hansen W, Crokaert F, Yourassowski E (1991) Evaluation of the E Test for quantitative antimicrobial susceptibility testing of Helicobacter pylori. J Clin Microbiol 29:2072-2075.

Graham DY \& Fischbach L (2010) Helicobacter pylori treatment in the era of increasing antibiotic resistance. Gut 59:11431153.

Grignon B, Tankovic J, Megraud F, Glupczynski Y, Husson MO, Conroy MC, Emond JP, Loulergue J, Raymond J, Fauchere JL (2002) Validation of diffusion methods for macrolide susceptibility testing of Helicobacter pylori. Microb Drug Resist 8:61-66.

Hachem CY, Clarridge JE, Reddy R, Flamm R, Evans DG, Tanaka SK, Graham DY (1996) Antimicrobial susceptibility testing of Helicobacter pylori: Comparison of E-test, broth microdilution, and disk diffusion for ampicillin, clarithromycin, and metronidazole. Diagn Microbiol Infect Dis 24:37-41.

Jones NL, Sherman P, Fallone CA, Flook N, Smail F, van Zanten SV, Hunt R, Thomson A (2005) Canadian Helicobacter Study Group Consensus Conference: Update on the approach to Helicobacter pylori infection in children and adolescents - An evidence-based evaluation. Can J Gastroenterol 19:399-408.

Kalach N, Benhamou PH, Bergeret M, Gottrand F, Husson MO, Barbier C, Dupont C, Raymond J (2002) Acquisition of secondary resistance after failure of a first treatment of Helicobacter pylori infection in children. Arch Pediatr 9:130-135.

Lang L \& Garcia F (2004) Comparison of E-test and disk diffusion assay to evaluate resistance of Helicobacter pylori isolates to amoxicillin, clarithromycin, metranidazole and tetracycline in Costa Rica. International $\mathrm{J}$ Antimicrobial Agents 24:571-577.

Malfertheiner P, Megraud F, O'Morain CA, Atherton J, Axon ATR, Bazzoli F, Gensini GF, Gisbert JP, Graham DY, Rokkas T, El-Omar EM, Kuipers EJ and The European Helicobacter Study Group (EHSG) (2012) Management of Helicobacter pylori infection: The Maastricht IV/ Florence Consensus Report. Gut 61:646-664.

Mégraud F (2004) H pylori antibiotic resistance: Prevalence, importance, and advances in testing. Gut 53:1374-1384.

Mégraud F \& Lehours P (2007) Helicobacter pylori detection and antimicrobial susceptibility testing. Clin Microbiol Reviews 20:280-292.

Mendonça S, Ecclissato C, Sartori MS, Godoy APO, Guerzoni RA, Degger M, Pedrazzoli Jr J (2000) Prevalence of Helicobacter pylori resistance to metronidazole, clarithromycin, amoxicillin, tetracycline, and furadolidone in Brasil. Helicobacter 5:79-83. 
Midolo PD, Bell JM, Lambert JR, Turnidge JD, Grayson ML (1997) Antimicrobial resistance testing of Helicobacter pylori: A comparison of Etest and disk diffusion methods. Pathology 29:411-414.

Mishra KK, Srivastava S, Garg A, Ayyagari A (2006) Antibiotic susceptibility of Helicobacter pylori clinical isolates: Comparative evaluation of disk-diffusion and E-test methods. Current Microbiol 53:329-334.

Molina-Infante J \& Gisbert JP (2013) Actualización de la eficacia de la terapia triple para la infección por Helicobacter pylori y de la resistencia a claritromicina en España (2007-2012). Gastroenterología y Hepatología 36: 375-381.

National Committee for Clinical Laboratory Standards (2000) Performance standards for antimicrobial susceptibility testing. Approved standard M7-A5. Informational supplement M100-S10. NCCLS, Wayne.

Nguyen TVH, Bengstsson C, Yin L, Nguyen GK, Hoanh TTH, Phung DC, Sorberg M, Granstrom M (2012) Eradication of Helicobacter pylori in children in Vietnam in relation to antibiotic resistance. Helicobacter 17:319-325.

Ogata SK, Godoy APO, da Silva Patricio FR, Kawakami E (2013) High Helicobacter pylori resistance to metronidazole and clarithromycin in Brazilian children and adolescents. J Pediatr Gastroenterol Nutr 56:645-648.

Osato MS (2000) Antimicrobial susceptibility testing for Helicobacter pylori: Sensitivity test results and their clinical relevance. Current Pharmaceutical Design 6:1545-1555.
Sherif M, Mohran Z, Fathy H, Rockabrand DM, Rozmajzl PJ, Frenck RW (2004) Universal high-level primary metronidazole resistance in Helicobacter pylori isolated from children in Egypt. J Clin Microbiol 42:4832-4834.

Sung H, Kang J-O, Lee J, Lee HK, Lee M-K, Lim J-H, Kim M-N and Helicobacter Study Group (2009) Clarithromycin and amoxicillin susceptibility testing of Helicobacter pylori by disk diffusion method. Korean J Clin Microbiol 12:30-36.

Sykora J \& Rowland M (2011) Helicobacter pylori in pediatrics. Helicobacter 16:59-64.

Tankovic J, Lamarque D, Lascols C, Soussy CJ, Delchier JC (2001) Impact of Helicobacter pylori resistance to clarithromycin on the eficcacy of the omeprazole-amoxicillin-clarithromycin therapy. Aliment Pharmacol Ther 15:707-713.

Warburton-Timms VJ \& McNulty CA (2001) Role of screening agar plates for in vitro susceptibility testing of Helicobacter pylori in a routine laboratory setting. J Clin Pathol 54:408-411.

Wong WM, Gu Q, Wang WH, Fung FM-Y, Berg DE, Lai KC, Xia $\mathrm{HH}-\mathrm{X}, \mathrm{Hu}$ WHC, Chan $\mathrm{CH}$, Chan AO-O, Yuen M-F, Hui C-K, Lam SK, Wong BC-Y (2003) Effects of primary metronidazole and clarithromycin resistance to Helicobacter pylori on omeprazole, metronidazole, and clarithromycin triple-therapy regimen in a region with high rates of metronidazole resistance. CID 37:882-889.

All the content of the journal, except where otherwise noted, is licensed under a Creative Commons License CC BY-NC. 